\title{
The Emergence of Geroscience as an Interdisciplinary Approach to the Enhancement of Health Span and Life Span
}

\author{
Felipe Sierra \\ Division of Aging Biology, National Institute on Aging, National Institutes of Health, \\ Bethesda, Maryland, 20892 \\ Correspondence: sierraf@nia.nih.gov
}

\begin{abstract}
Research on the biology of aging has accelerated rapidly in the last two decades. It is now at the point where translation of the findings into useful approaches to improve the health of the elderly population seems possible. In trying to fill that gap, a new field termed geroscience will be articulated here that attempts to identify the biological underpinnings for the agedependency of most chronic diseases. Herein, I will review the major conceptual issues leading to the formulation of geroscience as a field, as well as give examples of current areas of inquiry in which basic aging biology research could lead to therapeutic approaches to address age-related chronic diseases, not one at a time, but most of them in unison.
\end{abstract}

$T_{1}^{\mathrm{h}}$ he field of aging biology has exploded in the last few decades, with the initial focus on descriptive work that catalogued the myriad changes that occur during aging, first leading to a highly mechanistic phase in which the major molecular and cellular determinants of the process were identified, and to the current stage in which, without neglecting the still very unfinished mechanistic and discovery work, some of the findings are poised for possible application in humans. An interesting outcome of the descriptive work was the realization that not all age-related changes are necessarily bad for the organism. Although some phenomena appear indeed to be at least partially responsible for increasing the risk for age-related disease (e.g., the decrease in proteostasis leading to neurodegenerative diseases characterized by accumulation of misfolded proteins), others are neutral (cosmetic changes like hair graying) and, in fact, some of the changes appear to be adaptive to other changes occurring with age and as such, they might be beneficial to the health of the organism (changes in some hormones, e.g., such as possibly testosterone or insulin-like growth factor [IGF]) (Rincon et al. 2005; Corona et al. 2013; Matsumoto 2013). Other changes are the result of pathology and are therefore independent of the aging process per se, yet they are difficult to separate in the case of highly prevalent diseases and conditions. In that sense, the definition by Harrison is appropriate: "aging is what occurs to all individuals of a given species, while disease occurs to only a proportion of them" (Flurkey et al. 2007).

Although some fields, such as caloric restriction, cell senescence, and the free radical hypothesis, were potent initial drivers of

Editors: S. Jay Olshansky, George M. Martin, and James L. Kirkland

Additional Perspectives on Aging available at www.perspectivesinmedicine.org

Copyright (C) 2016 Cold Spring Harbor Laboratory Press; all rights reserved; doi: 10.1101 /cshperspect.a025163

Cite this article as Cold Spring Harb Perspect Med 2016;6:a025163 
F. Sierra

research into the biology of aging, the main transformative research leading to the current status was the genetic work initially encouraged by the National Institute of Agings's (NIA) Longevity Assurance Genes Initiative (LAG). Although presently we know of several hundred genes that, when modified, can increase life span in animal models (Kenyon 2010; genomics .senescence.info/genes/stats.php), and some variants of these genes have been identified in long-lived humans (Pawlikowska et al. 2009; Slagboom et al. 2011; Wheeler and Kim 2011; Milman et al. 2014), in the late 1990s there was widespread skepticism that even a single gene would be found, despite common recognition of the partially inheritable nature of longevity. The finding of molecular drivers of the process brought aging biology research into the mainstream and has resulted in the current renaissance of the field. The historical events leading to the current state of affairs have been reviewed previously and will not be repeated here (Warner 2005). Rather, I will focus on a discussion of the origins of geroscience and the importance of studying aging at the most basic biological level. I will finish with some reference to the main current areas of research, as identified during a recent summit organized by the trans-NIH (National Institutes of Health) GeroScience Interest Group (biomedgerontology.oxfordjournals.org/ content/69/Suppl_1.toc).

\section{Geroscience}

The quest for eternal youth is as old as humanity itself. In fact, we have known for centuries that life span (and health span) can be extended, within limits, simply by adopting moderate changes in lifestyle, including diet and exercise. Unfortunately, this is easier said than done. Although public policy has shown that it is actually possible to change most people's behaviors when they understand it is in their own interest (seat belts, smoking, and laying babies in their backs represent successful recent examples), reversing behaviors that include both quantitatively and qualitatively unhealthful habits concerning diet and exercise is proving problematic for most people. For example, we know that in many laboratory animals, substantially reducing caloric intake extends life span and improves health in old age. Yet, few people would subject themselves to the harshness of that regime, and the entire area of dietary restriction (DR) is more suitable for experimental investigations than as a practical approach to human health.

The need to address the issues posed by the graying of the world's population is urgent. The dramatic increase in the proportion of people aged 65 or older (and the even more dramatic increase in those 85 and older, including centenarians) poses challenges that as a species we are not yet equipped to handle. Furthermore, neither our health care systems, nor the economy or the societal system will be able to sustain this unprecedented increase in the proportion of elders in the human population (Bhattacharya et al. 2004). In addition to the obvious need for more properly trained geriatricians and social workers, there is also a need to better understand the biology driving the aging process. Epidemiological studies suggest that aging might be the major risk factor for most agerelated chronic diseases (Niccoli and Partridge 2012). Experimental manipulation of the rate of aging in model organisms has borne that observation; increasing life span, which is assumed to either delay or slow down the process of aging, does indeed lead to a delay and softening of the diseases that normally accompany old age (Baur et al. 2006; Fernández and Fraga 2011; Wilkinson et al. 2012). Although these recent advances have made the idea of addressing the role of aging as the major risk factor for most chronic diseases closer to being feasible, the idea itself is not new. Indeed, the germ of the idea arose several decades ago, with the main concepts appearing as early as 1977 in a publication by Neugarten and Havighurst (1977). That idea was then further reformulated in 2006 in the form of the longevity dividend (Olshansky et al. 2006, 2007). Yet, recent advances have given the concept a more urgent and attainable form, exemplified by the current interest in the new field of geroscience, "an interdisciplinary field that aims to understand the relationship between aging and age-related 
diseases and disabilities" (en.wikipedia.org/ wiki/Geroscience).

The basic principles governing geroscience are simple: the ultimate goal of biomedical research is to improve the quality of life in humans, and because chronic diseases and conditions of the elderly represent the main hurdle toward reaching that goal, it follows that addressing these diseases should be-and is indeed-a priority. The twist comes with the concept that, because aging is malleable (at least in many animal models) and aging is also the main risk factor for those diseases and conditions, then addressing the basic biology of aging is likely to provide a better payoff than addressing diseases one at a time, as it is often done currently (Fig. 1). There are two major conceptual issues at play here. First is the complex nature of chronic diseases. Unlike infectious diseases or genetic disorders, chronic diseases of aging are multifactorial and complex. Although much research is devoted to fighting disease-specific risk factors (e.g., cholesterol and obesity for cardiovascular disease, amyloid $\beta$ (A $\beta$ ) for $\mathrm{Alz}$ heimer's, glucose handling for diabetes), there is a growing realization that, for those disease- specific risk factors to lead to disease, additional elements also need to be present, including both environmental factors and what has been called a "receptive environment," more often than not provided by age itself (Krtolica and Campisi 2003). As an additional example, unless it is driven by a congenital abnormality, cancer usually does not affect humans until their sixth or seventh decade, yet it occurs frequently in most mice by the age of 2 years; that is, in both species, cancer strikes most frequently when individuals are at $\sim 2 / 3$ of their expected life span. This difference could be driven, in part, by differences in repair rates (Kumar and Subramanian 2002; Gorbunova et al. 2014), and it has been shown that the rate of DNA repair changes with age (Gorbunova et al. 2007; Vaidya et al. 2014). These are still heavily debated topics (Promislow 1994; Jensen-Seaman et al. 2004). In addition, however, there is a striking commonality in that in both cases, cancer strikes when individuals are well past their midlife points. This suggests that for cancer to develop into a clinically recognizable disease, those mutated cells need to be in a "receptive environment."

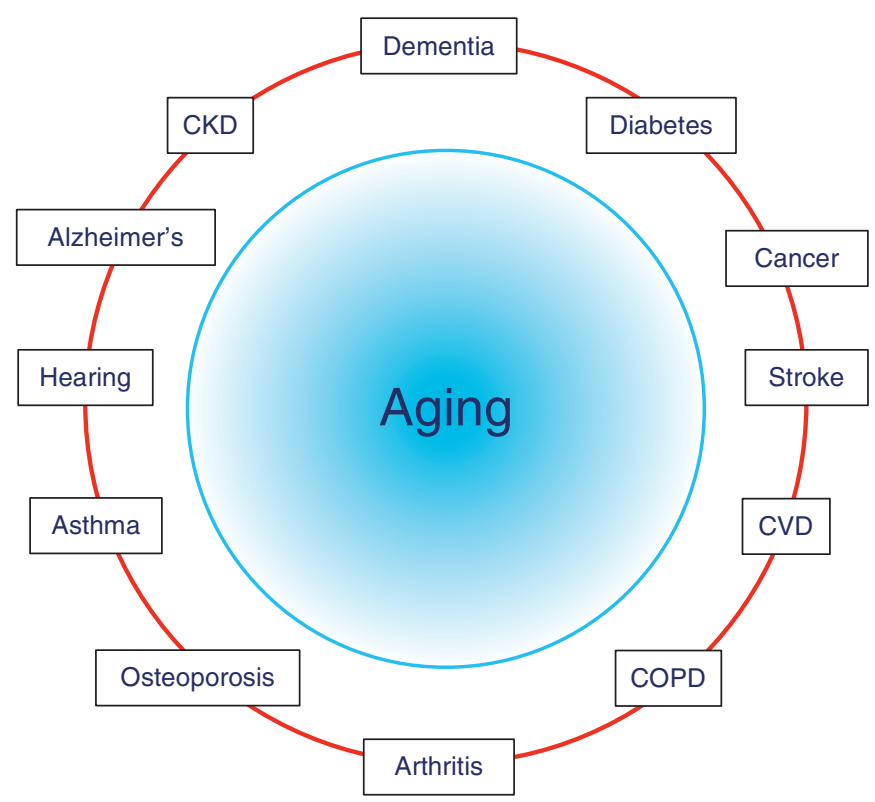

Figure 1. Aging is the major risk factor for most chronic diseases. CVD, Cardiovascular disease; COPD, chronic obstructive pulmonary disease; $\mathrm{CKD}$, chronic kidney disease. 
F. Sierra

A separate issue that makes geroscience timely is the fact of comorbidities, and the inadequacy of the current model of addressing one disease at a time. Much current research in biomedicine aims at preventing, curing, or managing one disease at a time (hence, the NIH has a cancer institute, a diabetes institute, etc., and this model is emulated across the world). In addition, there is an entrenched operating procedure in clinical trials, whereby patients suffering from diseases other than the one under study are not included (and often, neither are older patients). Yet, the diseases we are trying to address seldom occur in isolation, and seldom in patients of the ages studied. By embracing the fact that aging biology facilitates multiple comorbidities, geroscience aims at reversing these trends and putting the emphasis on preventing, curing, or delaying not one, but all chronic diseases at once. In doing so, geroscience intends to shift the focus away from specific diseases and their role in mortality, toward an assessment of overall health in which the individual's physiology will determine his/her overall risk for chronic diseases, irrespective of which disease is more likely to affect the individual based on genetic or environmental factors.

As will be discussed later in this review, there is now plenty of evidence that indicates that biological aging is malleable, and, more importantly, when aging is delayed, so are age-related diseases and conditions. In fact, aging can be delayed by behavioral (DR) (McCay and Crowell 1934; McCay et al. 1935), genetic (Kenyon 2010), and, to an extent, by pharmacological means, such as rapamycin (Harrison et al. 2009), acarbose (Harrison et al. 2014), metformin (Martin-Montalvo et al. 2013), and others, including resveratrol under metabolically stressed conditions (Baur et al. 2006; Pearson et al. 2008). Current research into pharmacological means of extending life span and health span take advantage of both molecular (target of rapamycin [TOR], IGF, sirtuins) and cellular (senescence, stem cells) discoveries and the field is poised for further findings during the next 10 years. Most importantly, in most cases studied, these manipulations lead to significant improvements in physiology, including enhanced resistance to disease (Baur et al 2006; Pearson et al. 2008; Baker et al. 2011; Fernández and Fraga 2011; Wilkinson et al. 2012; Martin-Montalvo et al. 2013).

It is common for people to question the goals of aging research, as most people-including the elderly-do not consider extending life span to be a worthy goal unless health span is improved and extended in parallel. Indeed, the goal of aging biology research, as well as geroscience, is not to increase life span (that is used in research as an easy-to-measure, binary surrogate), but, rather, to understand aging biology so as to improve health span and delay disease. The consequences of aging can be summarized as an increase in frailty and an attendant decrease in resilience, leading on the one hand to increased susceptibility to disease (frailty), and, on the other, to decreased ability to withstand the concomitant stress caused by disease (resilience). Together, these changes result in a decrease in the thresholds necessary for disease-specific insults to result in overt pathology. This explains, for example, why a given level of cholesterol, or burden of $A \beta$ or oncogenic mutations, can be an asymptomatic risk factor in younger individuals, but disease causing in older counterparts. Similarly, the change in thresholds at which challenges can be overcome explains why, for example, a young person recuperates easily from a period being bedridden, while the same challenge can become a chronically unsurmountable block for an older individual. Approaches that target either of these characteristics of the aging process are thus likely to result in decreased disease burden.

So, what will happen if geroscience is successful? If most chronic diseases are indeed postponed as a group, then it follows that life span will also increase, and it has been argued that this will further exacerbate the silver tsunami currently underway, with dramatic shifts in population stratification by age (Mendelson and Schwartz 1993). Although that is certainly true, the fallacy is to think of these "elderly" in current terms, as sick and frail. As it has been observed in multiple studies in mice and other species, addressing aging (as opposed to addressing one disease at a time) leads to robust 
elderly individuals, not sick ones (Baur et al. 2006; Pearson et al. 2008; Baker et al. 2011; Fernández and Fraga 2011; Wilkinson et al. 2012; Martin-Montalvo et al. 2013). In that scenario, the "new elderly" will not produce an undue burden on the health system or pensions, and in fact studies have shown that the opposite is true. Although curing cancer or cardiovascular disease (or both) would actually lead to a significant reduction in the number of people disabled from these often fatal conditions, the survivors would be disabled by other conditions later in life. The overall tradeoff would be negative (Miller 2002; Goldman et al. 2013). This occurs because curing one fatal disease allows the person to live longer but in the presence of other comorbid disabilities and conditions such as sarcopenia, osteoporosis, sensory loss, and others that, although not life threatening, considerably decrease the quality of life for so many elderly. If cured of only one fatal disease, individuals will keep on living with the other limitations until the next life-threatening disease (Alzheimer's, diabetes, cancer, etc.) does kill them.

In summary, geroscience aims at seeking innovative approaches to better identify the relationships between the biological processes of aging and the biological processes of age-related chronic diseases and disabilities, and, in so doing, we hope to understand why the former is the major risk factor for the latter. The underlying assumption is that these processes are likely to share much in common and to intersect and influence each other in manners that can be approached, experimentally first, and clinically in the not-too-distant future.

Based on these considerations, in 2011, we initiated a group internal to the NIH, dubbed the "GeroScience Interest Group" or GSIG. The purpose was to develop a collaborative framework that includes several NIH institutes with an interest in the biological mechanisms that drive the appearance of multiple diseases expressed in people of all ages, especially the elderly, with the aim of accelerating and coordinating efforts to promote further discoveries on the common risks and mechanisms behind such diseases. The goals of the GSIG are: (1) to promote discussion, sharing of ideas, and coordination of activities within the NIH, relating to the specific needs of the research community working on mechanisms underlying agerelated changes, including those that could lead to increased disease susceptibility; (2) to raise awareness, both within and outside the $\mathrm{NIH}$, of the relevant role played by aging biology in the development of age-related processes and chronic disease; (3) to develop potential public/private partnerships through interactions with scientific societies, industry, and other institutions with related interests; and (4) to develop trans-NIH funding initiatives that will encourage research on the basic biology of aging and its relationship to earlier life events, exposures, and diseases that will advance the goals and vision of the GSIG, and which complement and enhance the goals and vision of concerned institutes and centers (ICs).

The GSIG idea was received enthusiastically by several NIH directors and the group quickly grew to include official representatives from 20 different NIH institutes (for a complete list, please visit the GSIG website sigs.nih.gov/ geroscience/Pages/default.aspx). In addition to activities designed to awaken interest in the topic within the NIH (seminars, forums, etc.), the GSIG organized a workshop in 2012 on "inflammation and age-related diseases," which resulted in a publication (Howcroft et al. 2013) and a funding announcement joined by eight NIH institutes (PAR-13-233, Chronic Inflammation and Age-related Disease). The group's next major activity was the organization of a summit in 2013, called "Advances in Geroscience: Impact on Healthspan and Chronic Disease." The meeting was held on the NIH campus in Bethesda and, after a series of keynote speeches, including the NIH Director Dr. Francis Collins, the main meeting focused on seven major areas of research encompassing mechanisms driving aging and most likely being involved in enabling chronic diseases. These areas overlap significantly with the topics identified by López-Otín et al. (2013) in a recent opinion piece titled "The Hallmarks of Aging," and a series of opinion pieces from the chairs of each session from the summit was published 
F. Sierra

as a special issue of The Journals of Gerontology-Biological Sciences (Burch et al. 2014; biomedgerontology.oxfordjournals.org/content/ 69/Suppl_1.toc). A white paper summarizing the discussions from an ensuing executive session has been accepted for publication in the journal Cell (Kennedy et al. 2014). Some major aspects from these discussions are presented below.

\section{The Main Pillars of Research on Aging Biology}

It should be noted that the goal of geroscience (and the summit) is not to identify markers of aging, but rather, the goal has been to identify possible drivers of the process. Nevertheless, the search for biomarkers remains an underappreciated area of research that deserves more attention. For years, biogerontologists have shied away from this line of research, under the assumption that such markers would be too elusive. Novel technical developments, such as multiple omics technologies, now open new possibilities that need to be explored, because in the absence of such markers, progress in the field remains hindered. On the other hand, it is expected that identification and further enhancement of our knowledge about the mechanistic drivers of the aging process, as well as their interactions, will lead to possible therapeutics to delay aging and with that, concomitantly delay the onset and/or severity of multiple chronic diseases and conditions that affect primarily the older population. Major areas currently considered as potential drivers, and discussed at the 2013 summit, include inflammation, responsiveness to stress, epigenetics, metabolism, macromolecular damage, proteostasis, and stem cells (Fig. 2). A brief overview of current thoughts about each of these topics follows.

\section{Inflammation}

The inflammatory response is crucial as a first level of defense of the organism against aggression by pathogens and recovery from tissue damage. Thus, it appears important that the acute inflammatory response be maintained even into old age. The molecular and cellular mechanisms involved in this response have been well studied in young organisms and a proper response is both swift and short-lived. Aged organisms appear quite capable of mounting a response to most challenges, although the response is not always "normal," with some aspects exacerbated and others blunted ( $\mathrm{Wu}$ et al. 2007). However, in many instances, old organisms fail in the "shutting-off" phase of the response, leading to a lingering residue often called "sterile inflammation" (De Martinis

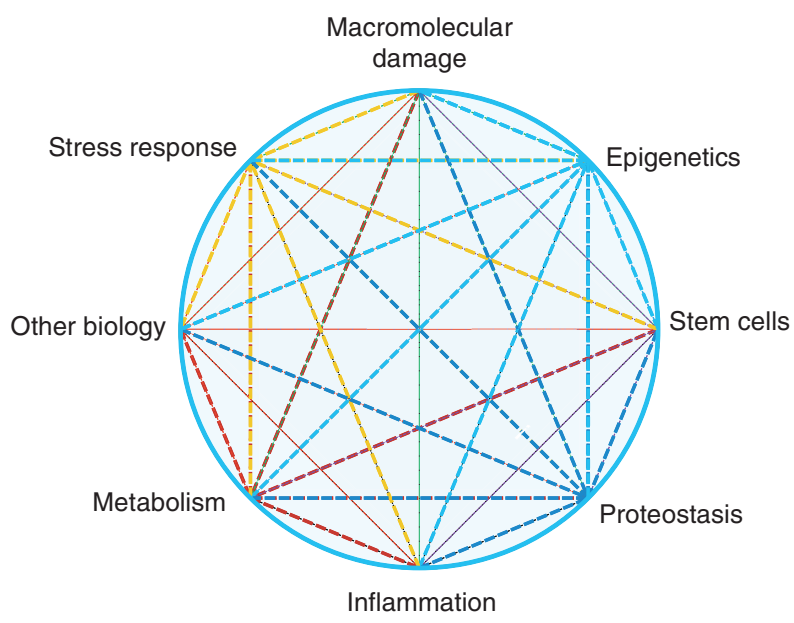

Figure 2. The main pillars of geroscience research. Aging physiology results from multiple interconnections among these pillars, including "other biology," to indicate our incomplete knowledge about the process. 
et al. 2005). This is characterized by mild-but chronic-elevation in the serum levels of several cytokines and acute phase factors, the most studied being interleukin (IL)-6, tumor necrosis factor $\alpha(\mathrm{TNF}-\alpha)$ and C-reactive protein (CRP) (Ferrucci et al. 1999; Harris et al. 1999; Bruunsgaard and Pedersen 2003; Bruunsgaard et al. 2003; Franceschi 2007). It is generally believed that this age-related low grade chronic inflammation (also termed "imflammaging" [Franceschi et al. 2007; Pawelec et al. 2014]) might be a significant contributing factor to several chronic diseases and conditions (Tchkonia et al. 2013; Franceschi and Campisi 2014). Efforts at curbing the inflammatory response are currently ongoing in the clinic, with 20 such trials currently listed in clinicaltrials.gov (clinicaltrials.gov/ct2/results?term=inflammation \&search=search). However, considerable additional research is needed, including the identification of the source of cytokines (they do not appear to be derived from the classical source, macrophages, and both senescent cells and adipocytes are currently being investigated) (Howcroft et al. 2013; Franceschi and Campisi 2014). In addition, an important consideration is whether an intervention should be sought that dampens the inflammatory response altogether (e.g., anti-inflammatories) or whether a more appropriate approach might be represented by interventions that allow the response to proceed normally but improve the effectiveness of the shutting off mechanisms. In addition, whether sterile inflammation is really a maladaptive response needs to be clarified. Several lines of evidence indicate that reducing inflammation might be beneficial in terms of many diseases (Franceschi and Campisi 2014), but it is still entirely possible that this low level inflammation might be an adaptive response to age- or disease-induced tissue damage, and that reducing it might lead to unforeseen complications.

\section{Adaptation to Stress}

Stress is an inevitable part of life, for humans as well as other species. At the molecular level, cells are constantly bombarded with stressors including free radicals, environmental toxins,
UV light, and others, although organisms are additionally exposed to cold, heat, and psychological stress in the form of predators, starvation, etc. Chronic, both physiological and psychological, stressors appear to accelerate the rate of aging (McEwen 2013; Epel and Lithgow 2014), and recent exciting work is beginning to show the interrelations between psychological stress and molecular responses, such as telomere shortening (Epel et al. 2004; Aydinonat et al. 2014; Zalli et al. 2014). It seems likely, but still unproven, that many-if not allstresses might elicit a response from the organism via common mechanisms, and a further examination of these mechanisms is likely to yield insights into basic aging processes. If so, then the source of stress becomes less relevant and it is entirely possible that the focus might shift toward the mechanisms of response and coping. Because stress can be lowered but not eliminated, interventions aimed at increasing the ability of the organism to respond to stress might be more useful in our efforts to live to an old age in good health. Interestingly, both physiological and psychological stresses come in two very distinct flavors: mild stresses appear to be beneficial, probably through mechanisms related to hormesis (Calabrese et al. 2012). In contrast, both powerful acute or mild chronic stresses are detrimental (McEwen 2013; Epel and Lithgow 2014). A critical unanswered question is the identification of mechanisms that control that switch, and whether this switch can be manipulated so as to increase the positive and decrease the negative. This area of research is currently largely unexplored.

\section{Epigenetics}

The discovery of genes and pathways capable of increasing life span in a conserved fashion across many species was crucial in turning aging research from the descriptive to the mechanistic phase. Modern high throughput technologies have moved these discoveries into humans, in which some variants of genes initially described in lower organisms have been shown to be associated with extreme longevity (centenarians) (Wheeler and Kim 2011). More recent work in 
F. Sierra

lower organisms has somewhat shifted toward the more malleable epigenome, in which significant changes have been described to occur as a function of age (Rando and Chang 2008; Wood et al. 2010; Greer et al. 2011; Kato et al. 2011). The origin of these changes and their downstream effects are currently the subject of intense study. Epigenetic changes have also been associated with a number of age-related diseases such as cancer, and the interrelationships between epigenetic changes caused by aging and those by disease are being explored (Brunet and Berger 2014). Because it is generally believed that epigenetic marks might integrate complex responses to the environment, another active area of research is the resolution between beneficial versus deleterious adaptations to stress, establishing to what extent these epigenetic changes can drive pathology, and to what extent those changes might be reversible or modifiable through pharmaceutical interventions.

\section{Metabolism}

Metabolic changes with age are widespread and in many cases they have been associated with age-related diseases, including diabetes, cancer, cardiovascular and neurodegenerative diseases, some of which are not classically considered "metabolic diseases." In fact, many of the genetic pathways affecting longevity have critical roles in the regulation of metabolism, including the insulin/IGF (Johnson 2008; Fontana et al. 2010; Barzilai et al. 2012) and mTOR (Harrison et al. 2009; Johnson et al. 2013; Miller et al. 2014) pathways, and the best characterized way of extending life span, caloric restriction, should be considered first and foremost a metabolic intervention. Another pathway that affects aging, sirtuins, has also been shown to have dramatic interactions with cellular metabolism, probably via regulation of $\mathrm{NAD}^{+}$levels, although this is still a subject of intense study (de Cabo et al. 2014; Imai and Guarente 2014; Rehan et al. 2014). It is telling that resveratrol, a molecule first studied because of its ability to activate sirtuins, extends life span in mice, but only if the animals are under severe metabolic stress (Baur et al. 2006). Additional metabolic changes during aging are just now being identified, such as changes in circadian rhythms and changes in the microbiome, both of which might have dramatic metabolic effects. The roles of circadian clocks, changing microbiomes and changing intestinal leakiness in aging and agerelated disease are likely to be extensively explored in the near future, and they are likely to have dramatic effects on metabolism, inflammation, and other aspects of aging. Because of their pivotal role in intracellular energy production, mitochondria have also been studied extensively in relationship to aging. Contrary to expectations, reducing the activity of the mitochondrial electron transport chain leads to increased longevity (Rea 2005; Munkácsy and Rea 2014), as do manipulations that slightly increase free radical production (Ristow and Schmeisser 2011).

\section{Macromolecular Damage}

The free radical theory of aging has been a cornerstone of aging biology research for more than half a century. In its simplest form, the theory posits that respiration-produced free radicals lead to macromolecular damage, and this damage results in the cellular and tissue loss-of-function observed during aging. Recent evidence coming from experiments in mice genetically manipulated to either increase or decrease free radical scavenging have put the theory into question, because most of these manipulations did indeed lead to the expected changes in macromolecular damage (decrease or increase, respectively) but did not affect either mean or maximal life span (Van Remmen et al. 2003; Pérez et al. 2009). A notable exception is the mCAT mouse model, in which expression of catalase in the mitochondria (but not other subcellular compartments) does indeed lead to increased longevity and a decrease in at least some age-related pathology, including cardiovascular disease (Schriner et al. 2005). Nevertheless, many studies have correlated free-radical damage with various age-related diseases, including cancer and cardiovascular diseases, the main killers in the Western world (Pala and Gürkan 2008). It remains to be 
seen whether free radical-driven damage can affect survival under conditions less pristine than IACUC (Institutional Animal Care and Use Committee)-approved mouse housing. Other molecular damage, such as DNA damage driven by mutations in either mitochondrial or nuclear DNA repair systems do lead to what some investigators have called "accelerated aging" (Trifunovic et al. 2004; Wallace 2005; Hoeijmakers 2009), and in independent research, it has been found that many human accelerated aging syndromes (Hutchinson-Gilford, Werner, Cockayne, and others) are characterized by mutations in genes involved in DNA repair or other DNA transactions, including structural integrity of the nuclear lamina (Rodríguez and Eriksson 2010; Worman 2012). As with response to stress, it remains to be seen whether the apparent acceleration of aging phenotypes in these instances is directly the result of DNA damage, or if it is rather the cell's response to that damage (for example, by apoptosis or senescence, leading to stem-cell depletion and/or inflammatory responses) that is directly responsible for the phenotype (Sierra 2006). An emerging area related to macromolecular damage is telomere integrity. Telomere shortening leads, in vitro at least, to cellular senescence (Bodnar et al. 1998), and telomere length has been associated with susceptibility to a variety of diseases (Cawthon et al. 2003; Epel et al. 2009). Whether sufficient to lead to that particular outcome or not, telomere shortening has been clearly associated with chronological aging and, perhaps more interestingly, it has been found that telomere shortening is accelerated by psychological stress (Herrera et al. 1999; Blasco 2007; Parks et al. 2009; Zalli et al. 2014). Whether causative or solely a biomarker, these findings are exciting and further research in this domain is likely to shed light on these relationships within the next few years.

\section{Proteostasis}

Just like the emphasis in the field of stress is shifting from stress itself toward the role of the response to stress, so is research on macromolecular damage shifting toward the mechanisms that control such damage. Proteostasis includes those mechanisms responsible for preserving the health of the proteome, including chaperones, autophagy, proteosomal degradations and others (Balch et al. 2008; Breusing and Grune 2008; Cuervo 2008; Morimoto and Cuervo 2014). A prominent role in aging has been ascribed to these mechanisms, including the unfolded protein response (UPR), both at the level of endoplasmic reticulum (ER) and mitochondria (for the moment; others such as nuclear UPR are likely to come to the fore in the near future). Changes in these processes are clearly related to age-related diseases including neurodegenerative and other diseases characterized by the accumulation of intracellular or extracellular aggregates, and it seems clear that modification of proteostasis represents an exciting possible therapeutic target. The possible role of proteostatic mechanisms in aging and age-related diseases is twofold, because not only is there a general decrease in the activity of the many protein quality control pathways with aging, but, in addition, there is an increased burden because of the accumulation of damaged proteins that need to be dealt with. So, aging organisms are confronted with a complex risk of losing protein quality control. On the positive side, this means that the problems of protein aggregation can be attacked on two fronts: decrease the damage or increase the defenses. Much recent effort has been placed in reducing the damage. Efforts at boosting the defenses are just starting. Exciting recent results indicate that the various protein quality control machineries can interact and supplement each other, even at a distance (Wong and Cuervo 2010; Durieux et al. 2011; Dillin et al. 2014). This gives hope that improving the entire system might not require a massive revamping of all the defective components, but partial alleviation in some crucial pathways and in relevant tissues might be sufficient to improve quality control even in tissues in which the system has not been specifically modified.

\section{Stem Cells and Regeneration}

Stem cells have generated much excitement both among scientists and the public alike, 
F. Sierra

based on their promise as therapeutic agents for a wide range of diseases. In the case of chronic age-related diseases, that excitement needs to be tempered by an assessment of what happens with stem cells during aging. Elegant experiments using heterochronic parabiosis have shown that, at least in some tissues such as muscle and brain, the problem with aging is less with the stem cells themselves, but rather with their niche (Conboy et al. 2005). In other words, it appears that, in some cases, stem cells are still present in aged individuals, but their niche is incapable of activating them. Encouraging results from parabiosis experiments indicate that there are circulating factors capable of either activating or inhibiting stem cells (Villeda et al. 2011, 2014; Loffredo et al. 2013; Katsimpardi et al. 2014), and further detailing the relative importance of stem cells and their niches in different tissues and in different diseases will be crucial to better define useful therapies. Interestingly, it is likely that modifying the niche might be easier than injecting young stem cells, which in fact might not be effective in cases in which the niche is not receptive. A separate, exciting area of research involves induced pluripotent stem cells (iPSC) (Liu et al. 2012; Mahmoudi and Brunet 2012; Isobe et al. 2014). The availability of iPSC will most likely become an important tool in research aimed at identifying genetic determinants of age-related diseases, as well as possible therapeutic tools for at least a subset of complex chronic diseases. The field of stem-cell research is still in a rapid expansion phase and there are many areas still to be investigated, including the genetic basis for the decrease in their effectiveness with aging, their role in maintaining tissue function during aging in the absence of injury, and their impact on metabolism, inflammation, etc., and vice versa.

The areas discussed above are by no means all there is to learn about the basic biology of aging. Many additional leads and fields are continuously providing new information and there is no possibility of discussing them all in here. For example, no mention has been made of the findings coming from comparative biology, or the use of novel animal models. Similarly, no discussion has been included about the notable contributions of classical evolutionary biology or demography, fields that certainly shape the theoretical and conceptual contexts within which aging biology research is conducted. Comprehensive approaches, including systems biology, are also becoming an important aspect that will need to be developed to address important areas in the field. Finally, the importance of cross talk between basic researchers and clinicians working with elderly patients cannot be overemphasized.

\section{CONCLUDING REMARKS}

The fact that aging is the major risk factor for most chronic diseases and conditions has been known since the early days of civilization. However, because aging is usually understood as the chronological passing of time, rather than an integrated biological process, aging has traditionally been viewed-by physicians and the general public alike - as immutable. In contrast to chronological aging, however, recent research has shown that the rate of physiological aging can be manipulated by a variety of behavioral, genetic, and pharmacological means in many animal models, and there is reason to believe this can be accomplished in humans. Most importantly, when the rate of aging is decreased in animal models, there is often a delay (and decreased severity) of a number of age-associated diseases and conditions, suggesting that manipulations that either delay the onset or decrease the rate of aging could have a significant beneficial effect on the well-being of the elderly population.

In this review, I have described the currently recognized major pillars of aging, namely, inflammation, response to stress, epigenetics, metabolism, macromolecular damage, proteostasis, and stem cells. Recent discoveries in each of these domains, as well as novel approaches, should facilitate the elucidation of potential interventions in one or other of these pillars, so as to favorably alter the onset or progression of multiple chronic diseases affecting the elderly. Given the current demographic trends in human populations, there is an urgent need to develop these ideas into clinical practice. 


\section{REFERENCES}

Aydinonat D, Penn DJ, Smith S, Moodley Y, Hoelzl F, Knauer F, Schwarzenberger F. 2014. Social isolation shortens telomeres in African grey parrots (Psittacus erithacus erithacus). PLoS ONE 9: e93839.

Baker DJ, Wijshake T, Tchkonia T, LeBrasseur NK, Childs BG, van de Sluis B, Kirkland JL, van Deursen JM. 2011. Clearance of $\mathrm{p} 16^{\mathrm{Ink} 4 \mathrm{a}}$-positive senescent cells delays ageing-associated disorders. Nature 479: 232-236.

Balch WE, Morimoto RI, Dillin A, Kelly JW. 2008. Adapting proteostasis for disease intervention. Science 319: 916919.

Barzilai N, Huffman DM, Muzumdar RH, Bartke A. 2012. The critical role of metabolic pathways in aging. Diabetes 61: 1315-1322.

Baur JA, Pearson KJ, Price NL, Jamieson HA, Lerin C, Kalra A, Prabhu VV, Allard JS, Lopez-Lluch G, Lewis K, et al. 2006. Resveratrol improves health and survival of mice on a high-calorie diet. Nature 444: 337-342.

Bhattacharya J, Cutler DM, Goldman DP, Hurd MD, Joyce GF, Lakdawalla DN, Panis CWA, Shang B. 2004. Disability forecasts and future Medicare costs. In Frontiers in health policy research (ed. Cutler DM, Garber AM), Vol 7, pp. 75-94. National Bureau of Economic Research, Cambridge, MA.

Blasco MA. 2007. Telomere length, stem cells and aging. Nat Chem Biol 3: 640-649.

Bodnar AG, Ouellette M, Frolkis M, Holt SE, Chiu CP, Morin GB, Harley CB, Shay JW, Lichtsteiner S, Wright WE. 1998. Extension of life-span by introduction of telomerase into normal human cells. Science 279: 349-352.

Breusing N, Grune T. 2008. Regulation of proteasome-mediated protein degradation during oxidative stress and aging. Biol Chem 389: 203-209.

Brunet A, Berger SL. 2014. Epigenetics of aging and agingrelated disease. J Gerontol A Biol Sci Med Sci 69: S17-S20.

Bruunsgaard H, Pedersen BK. 2003. Age-related inflammatory cytokines and disease. Immunol Allergy Clin North Am 23: 15-39.

Bruunsgaard H, Andersen-Ranberg K, Hjelmborg JB, Pedersen BK, Jeune B. 2003. Elevated levels of tumor necrosis factor alpha and mortality in centenarians. Am J Med 115: 278-283.

Burch J, Augustine AD, Frieden LA, Hadley E, Howcroft TK, Johnson R, Khalsa PS, Kohanski RA, Li XL, Macchiarini $\mathrm{F}$, et al. 2014. Advances in geroscience: Impact on healthspan and chronic disease. J Gerontol A Biol Sci Med Sci 69: S1-S3.

Calabrese EJ, Iavicoli I, Calabrese V. 2012. Hormesis: Why it is important to biogerontologists. Biogerontology 13: 215-235.

Cawthon RM, Smith KR, O’Brien E, Sivatchenko A, Kerber RA. 2003. Association between telomere length in blood and mortality in people aged 60 years or older. Lancet 361: 393-395.

Conboy IM, Conboy MJ, Wagers AJ, Girma ER, Weissman IL, Rando TA. 2005. Rejuvenation of aged progenitor cells by exposure to a young systemic environment. Nature 433: $760-764$.
Corona G, Vignozzi L, Sforza A, Maggi M. 2013. Risks and benefits of late onset hypogonadism treatment: An expert opinion. World J Mens Health 31: 103-125.

Cuervo AM. 2008. Autophagy and aging: Keeping that old broom working. Trends Genet 24: 604-612.

De Cabo R, Carmona-Gutierrez D, Bernier M, Hall MN, Madeo F. 2014. The search for antiaging interventions: From elixirs to fasting regimens. Cell 157: 1515-1526.

De Martinis M, Franceschi C, Monti D, Ginaldi L. 2005. Inflamm-ageing and lifelong antigenic load as major determinants of ageing rate and longevity. FEBS Lett 579: 2035-2039.

Dillin A, Gottschling DE, Nyström T. 2014. The good and the bad of being connected: The integrons of aging. Curr Opin Cell Biol 26: 107-112.

Durieux J, Wolff S, Dillin A. 2011. The cell-non-autonomous nature of electron transport chain-mediated longevity. Cell 114: 79-91.

Epel ES, Lithgow GJ. 2014. Stress biology and aging mechanisms: Toward understanding the deep connection between adaptation to stress and longevity. J Gerontol A Biol Sci Med Sci 69: S10-S16.

Epel ES, Blackburn EH, Lin J, Dhabhar FS, Adler NE, Morrow JD, Cawthon RM. 2004. Accelerated telomere shortening in response to life stress. Proc Natl Acad Sci 101: 17312-17315.

Epel ES, Merkin SS, Cawthon R, Blackburn EH, Adler NE, Pletcher MJ, Seeman TE. 2009. The rate of leukocyte telomere shortening predicts mortality from cardiovascular disease in elderly men. Aging (Albany) 1: 81-88.

Fernández AF, Fraga MF. 2011. The effects of the dietary polyphenol resveratrol on human healthy aging. Epigenetics 6: $870-874$

Ferrucci L, Harris TB, Guralnik JM, Tracy RP, Corti MC, Cohen HJ, Penninx B, Pahor M, Wallace R, Havlik RJ. 1999. Serum IL-6 level and the development of disability in older persons. J Am Geriatr Soc 47: 639-646.

Flurkey K, Currer JM, Harrison DE. 2007. The mouse in aging research. In The mouse in biomedical research (ed. Fox JG, et al.), 2nd ed., Vol. III, pp. 637-672. Academic, Burlington, MA.

Fontana L, Partridge L, Longo VD. 2010. Extending healthy life span-From yeast to humans. Science 328: 321-326.

Franceschi C. 2007. Inflammaging as a major characteristic of old people: Can it be prevented or cured? Nutr Rev 65: S173-S176.

Franceschi C, Campisi J. 2014. Chronic inflammation (inflammaging) and its potential contribution to age-associated diseases. J Gerontol A Biol Sci Med Sci 69: S4-S9.

Franceschi C, Capri M, Monti D, Giunta S, Olivieri F, Sevini F, Panourgia MP, Invidia L, Celani L, Scurti M, et al. 2007. Inflammaging and anti-inflammaging: A systemic perspective on aging and longevity emerged from studies in humans. Mech Ageing Dev 128: 92-105.

Goldman DP, Cutler D, Rowe JW, Michaud PC, Sullivan J, Peneva D, Olshansky SJ. 2013. Substantial health and economic returns from delayed aging may warrant a new focus for medical research. Health Aff (Millwood) 32: 1698-1705. 
F. Sierra

Gorbunova V, Seluanov A, Mao Z, Hine C. 2007. Changes in DNA repair during aging. Nucleic Acids Res 35: 74667474

Gorbunova V, Seluanov A, Zhang Z, Gladyshev VN, Vijg J. 2014. Comparative genetics of longevity and cancer: Insights from long-lived rodents. Nat Rev Genet 15: 531540 .

Greer EL, Maures TJ, Ucar D, Hauswirth AG, Mancini E, Lim JP, Benayoun BA, Shi Y, Brunet A. 2011. Transgenerational epigenetic inheritance of longevity in Caenorhab ditis elegans. Nature 479: 365-371.

Harris TB, Ferrucci L, Tracy RP, Corti MC, Wacholder S, Ettinger WH Jr, Heimovitz H, Cohen HJ, Wallace R 1999. Associations of elevated interleukin-6 and C-reactive protein levels with mortality in the elderly. Am J Med 106: $506-512$.

Harrison DE, Strong R, Sharp ZD, Nelson JF, Astle CM, Flurkey K, Nadon NL, Wilkinson JE, Frenkel K, Carter CS, et al. 2009. Rapamycin fed late in life extends lifespan in genetically heterogeneous mice. Nature 460: 392-395.

Harrison DE, Strong R, Allison DB, Ames BN, Astle CM, Atamna H, Fernandez E, Flurkey K, Javors MA, Nadon NL, et al. 2014. Acarbose, 17- $\alpha$-estradiol, and nordihydroguaiaretic acid extend mouse lifespan preferentially in males. Aging Cell 13: 273-282.

Herrera E, Samper E, Martín-Caballero J, Flores JM, Lee HW, Blasco MA. 1999. Disease states associated with telomerase deficiency appear earlier in mice with short telomeres. EMBO J 18: 2950-2960.

Hoeijmakers JH. 2009. DNA damage, aging, and cancer. New Engl J Med 361: 1475-1485.

Howcroft TK, Campisi J, Louis GB, Smith MT, Wise B, Wyss-Coray T, Augustine AD, McElhaney JE, Kohanski R, Sierra F. 2013. The role of inflammation in age-related disease. Aging 5: 84-93.

Imai SI, Guarente L. 2014. NAD ${ }^{+}$and sirtuins in aging and disease. Trends Cell Biol 24: 464-471.

Isobe KI, Cheng Z, Nishio N, Suganya T, Tanaka Y, Ito S. 2014. iPSCs, aging and age-related diseases. N Biotechnol 31: $411-421$

Jensen-Seaman MI, Furey TS, Payseur BA, Lu Y, Roskin KM, Chen CF, Thomas MA, Haussler D, Jacob HJ. 2004. Comparative recombination rates in the rat, mouse, and human genomes. Genome Res 14: 528-538.

Johnson TE. 2008. Caenorhabditis elegans 2007: The premier model for the study of aging. Exp Gerontol 43: 1-4.

Johnson SC, Rabinovitch PS, Kaeberlein M. 2013. mTOR is a key modulator of ageing and age-related disease. Nature 493: $338-345$.

Kato M, Chen X, Inukai S, Zhao H, Slack FJ. 2011. Ageassociated changes in expression of small, noncoding RNAs, including microRNAs, in C. elegans. RNA 17: 1804-1820.

Katsimpardi L, Litterman NK, Schein PA, Miller CM, Loffredo FS, Wojtkiewicz GR, Chen JW, Lee RT, Wagers AJ, Rubin LL. 2014. Vascular and neurogenic rejuvenation of the aging mouse brain by young systemic factors. Science 344: $630-634$

Kennedy BK, Berger SL, Brunet A, Campisi J, Cuervo AM, Epel ES, Franceschi C, Lithgow GJ, Morimoto RI, Pessin
JE, et al. 2014. Geroscience: Linking aging to chronic disease. Cell 159: 709-713.

Kenyon C. 2010. The genetics of aging. Nature 464: $504-$ 512.

Krtolica A, Campisi J. 2003. Integrating epithelial cancer, aging stroma and cellular senescence. Adv Gerontol 11: $109-116$.

Kumar S, Subramanian S. 2002. Mutation rates in mammalian genomes. Proc Natl Acad Sci 99: 803-808.

Liu GH, Ding Z, Izpisua-Belmonte JC. 2012. iPSC technology to study human aging and aging-related disorders. Curr Opin Cell Biol 24: 765-774.

Loffredo FS, Steinhauser ML, Jay SM, Gannon J, Pancoast JR, Yalamanchi P, Sinha M, Dall'Osso C, Khong D, Shadrach JL, et al. 2013. Growth differentiation factor 11 is a circulating factor that reverses age-related cardiac hypertrophy. Cell 153: 828-839.

López-Otín C, Blasco MA, Partridge L, Serrano M, Kroemer G. 2013. The hallmarks of aging. Cell 153: 1194-1217.

Mahmoudi S, Brunet A. 2012. Aging and reprogramming: A two-way street. Curr Opin Cell Biol 24: 744-756.

Martin-Montalvo A, Mercken EM, Mitchell SJ, Palacios HH, Mote PL, Scheibye-Knudsen M, Gomes AP, Ward TM, Minor RK, Blouin MJ, et al. 2013. Metformin improves healthspan and lifespan in mice. Nat Commun 4: 2192.

Matsumoto AM. 2013. Testosterone administration in older men. Endocrinol Metab Clin North Am 42: 271-286.

McCay CM, Crowell MF. 1934. Prolonging the life span. Sci Mon 39: 405-414

McCay CM, Crowell MF, Maynard LA. 1935. The effect of retarded growth upon the length of life span and upon the ultimate body size. J Nutr 10: 63-79.

McEwen BS. 2013. Brain on stress: How the social environment gets under the skin. Proc Natl Acad Sci 109: 1718017185.

Mendelson DN, Schwartz WB. 1993. The effects of aging and population growth on health care costs. Health Aff 12: $119-125$.

Miller RA. 2002. Extending life: Scientific prospects and political obstacles. Milbank Q 80: 155-174.

Miller RA, Harrison DE, Astle CM, Fernandez E, Flurkey K, Han M, Javors MA, Li X, Nadon NL, Nelson JF, et al. 2014. Rapamycin-mediated lifespan increase in mice is dose and sex dependent and metabolically distinct from dietary restriction. Aging Cell 13: 468-477.

Milman S, Atzmon G, Huffman DM, Wan J, Crandall JP, Cohen P, Barzilai N. 2014. Low insulin-like growth factor1 level predicts survival in humans with exceptional longevity. Aging Cell 13: 769-771.

Morimoto RI, Cuervo AM. 2014. Proteostasis and the aging proteome in health and disease. J Gerontol A Biol Sci Med Sci 69: S33-S38.

Munkácsy E, Rea SL. 2014. The paradox of mitochondrial dysfunction and extended longevity. Exp Gerontol 56: 221-233.

Neugarten BL, Havighurst RJ. 1977. Extending the human life span: Social policy and social ethics. National Science Foundation, Arlington, VA.

Niccoli T, Partridge L. 2012. Ageing as a risk factor for disease. Curr Biol 22: R741-R752. 
Olshansky SJ, Perry D, Miller RA, Butler RN. 2006. In pursuit of the longevity dividend. The Scientist 20: 28-36.

Olshansky SJ, Perry D, Miller RA, Butler RN. 2007. Pursuing the longevity dividend. Scientific goals for an aging world. Ann NY Acad Sci 1114: 11-13.

Pala FS, Gürkan H. 2008. The role of free radicals in ethiopathogenesis of diseases. Adv Molec Biol 1: 1-9.

Parks CG, Miller DB, McCanlies EC, Cawthon RM, Andrew ME, DeRoo LA, Sandler DP. 2009. Telomere length, current perceived stress, and urinary stress hormones in women. Cancer Epidemiol Biomarkers Prev 18: 551-560.

Pawelec G, Goldeck D, Derhovanessian E. 2014. Inflammation, ageing and chronic disease. Curr Opin Immunol 29: $23-28$.

Pawlikowska L, Hu D, Huntsman S, Sung A, Chu C, Chen J, Joyner AH, Schork NJ, Hsueh WC, Reiner AP, et al. 2009. Association of common genetic variation in the insulin IGF-1 signaling pathway with human longevity. Aging Cell 8: $460-472$.

Pearson KJ, Baur JA, Lewis KN, Peshkin L, Price NL, Labinskyy N, Swindell WR, Kamara D, Minor RK, Perez E, et al. 2008. Resveratrol delays age-related deterioration and mimics transcriptional aspects of dietary restriction without extending life span. Cell Metab 8: 157-168.

Pérez VI, Van Remmen H, Bokov A, Epstein CJ, Vijg J, Richardson A. 2009. The overexpression of major antioxidant enzymes does not extend the lifespan of mice. Aging Cell 8: 73-75.

Promislow DEL. 1994. DNA repair and the evolution of longevity: A critical analysis. J Theoret Biol 170: 291-300.

Rando TA, Chang HY. 2008. Aging, rejuvenation, and epigenetic reprogramming: Resetting the aging clock. Ann Rev Biochem 77: 727-754.

Rea SL. 2005. Metabolism in the Caenorhabditis elegans Mit mutants. Exp Gerontol 40: 841-849.

Rehan L, Laszki-Szcząchor K, Sobieszczańska M, Polak-Jonkisz D. 2014. SIRT1 and NAD as regulators of ageing. Life Sci 105: 1-6.

Rincon M, Rudin E, Barzilai N. 2005. The insulin/IGF-1 signaling in mammals and its relevance to human longevity. Exp Gerontol 40: 873-877.

Ristow M, Schmeisser S. 2011. Extending life span by increasing oxidative stress. Free Radic Biol Med 51: 327 336.

Rodríguez S, Eriksson M. 2010. Evidence for the involvement of lamins in aging. Curr Aging Sci 3: 81-89.

Schriner SE, Linford NJ, Martin GM, Treuting P, Ogburn CE, Emond M, Coskun PE, Ladiges W, Wolf N, Van Remmen H, et al. 2005. Extension of murine life span by overexpression of catalase targeted to mitochondria. Science 308: 1909-1911.

Sierra F. 2006. Is (your cellular response to) stress killing you? J Gerontol A Biol Sci Med Sci 61: 557-561.

Slagboom PE, Beekman M, Passtoors WM, Deelen J, Vaarhorst AA, Boer JM, van den Akker EB, van Heemst D, de Craen AJ, Maier AB, et al. 2011. Genomics of human longevity. Philos Trans R Soc Lond B Biol Sci 366: 35-42.
Tchkonia T, Zhu Y, van Deursen J, Campisi J, Kirkland J. 2013. Cellular senescence and the senescent secretory phenotype: Therapeutic opportunities. J Clin Invest 123: $966-972$.

Trifunovic A, Wredenberg A, Falkenberg M, Spelbrink JN, Rovio AT, Bruder CE, Bohlooly-Y M, Gidlöf S, Oldfors A, Wibom R, et al. 2004. Premature ageing in mice expressing defective mitochondrial DNA polymerase. Nature 429: 417-423.

Vaidya A, Mao Z, Tian X, Spencer B, Seluanov A, Gorbunova V. 2014. Knock-in reporter mice demonstrate that DNA repair by non-homologous end joining declines with age. PLoS Genet 10: e1004511.

Van Remmen H, Ikeno Y, Hamilton M, Pahlavani M, Wolf N, Thorpe SR, Alderson NL, Baynes JW, Epstein CJ, Huang TT, et al. 2003. Life-long reduction in MnSOD activity results in increased DNA damage and higher incidence of cancer but does not accelerate aging. Physiol Genomics 16: 29-37.

Villeda SA, Luo J, Mosher KI, Zou B, Britschgi M, Bieri G, Stan TM, Fainberg N, Ding Z, Eggel A, et al. 2011. The ageing systemic milieu negatively regulates neurogenesis and cognitive function. Nature 477: 90-94.

Villeda SA, Plambeck KE, Middeldorp J, Castellano JM, Mosher KI, Luo J, Smith LK, Bieri G, Lin K, Berdnik D, et al. 2014. Young blood reverses age-related impairments in cognitive function and synaptic plasticity in mice. Nat Med 20: 659-663.

Wallace DC. 2005. A mitochondrial paradigm of metabolic and degenerative diseases, aging, and cancer: A dawn for evolutionary medicine. Ann Rev Genet 39: 359-407.

Warner HR. 2005. Developing a research agenda in biogerontology: Basic mechanisms. Sci Aging Knowl Environ 44: pe33.

Wheeler HE, Kim SK. 2011. Genetics and genomics of human aging. Philos Trans R Soc Lond B Biol Sci 366: 43-50.

Wilkinson JE, Burmeister L, Brooks SV, Chan CC, Friedline S, Harrison DE, Hejtmancik JF, Nadon N, Strong R, Wood LK, et al. 2012. Rapamycin slows aging in mice. Aging Cell 11: 675-682.

Wong E, Cuervo AM. 2010. Integration of clearance mechanisms: The proteasome and autophagy. Cold Spring Harb Perspect Biol 2: a006734.

Wood JG, Hillenmeyer S, Lawrence C, Chang C, Hosier S, Lightfoot W, Mukherjee E, Jiang N, Schorl C, Brodsky AS, et al. 2010. Chromatin remodeling in the aging genome of Drosophila. Aging Cell 9: 971-978.

Worman HJ. 2012. Nuclear lamins and laminopathies. $J$ Pathol 226: 316-325.

Wu D, Ren Z, Pae M, Guo W, Cui X, Merrill AH, Meydani SN. 2007. Aging up-regulates expression of inflammatory mediators in mouse adipose tissue. J Immunol 179: 4829-4839.

Zalli A, Carvalho LA, Lin J, Hamer M, Erusalimsky JD, Blackburn EH, Steptoe A. 2014. Shorter telomeres with high telomerase activity are associated with raised allostatic load and impoverished psychosocial resources. Proc Natl Acad Sci 111: 4519-4524. 


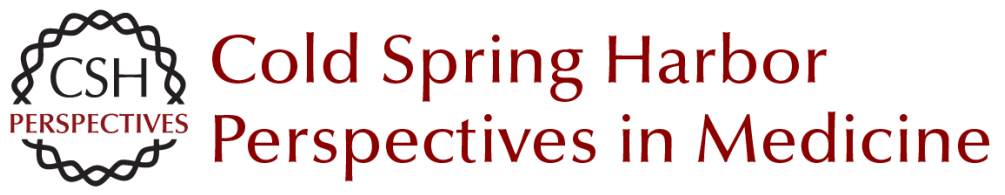

\title{
The Emergence of Geroscience as an Interdisciplinary Approach to the Enhancement of Health Span and Life Span
}

\author{
Felipe Sierra
}

Cold Spring Harb Perspect Med 2016; doi: 10.1101/cshperspect.a025163 originally published online March 1, 2016

\section{Subject Collection Aging}

\section{Personalized Financial Planning Using Applied \\ Genetics \\ S. Jay Olshansky, Bradley Willcox, Kirk Ashburn, et al.}

Biological Restraints on Indefinite Survival Jan Vijg and Steven N. Austad

The Role of the National Institute on Aging in the Development of the Field of Geroscience Felipe Sierra and Ronald A. Kohanski

The Funding Channels of Geroscience Stephanie Lederman

\section{Evolutionary Approaches in Aging Research Melissa Emery Thompson}

Interventions for Human Frailty: Physical Activity as a Model Linda P. Fried

How Research on Human Progeroid and Antigeroid Syndromes Can Contribute to the Longevity Dividend Initiative

Fuki M. Hisama, Junko Oshima and George M. Martin

Articulating the Case for the Longevity Dividend S. Jay Olshansky

\section{Funding Life-Extension Research Mehmood Khan}
Influence of Aging Science on Global Wealth
Management Michael Hodin

International Gains to Achieving Healthy

Longevity Andrew Scott, Julian Ashwin, Martin Ellison, et al.

From Life Span to Health Span: Declaring

"Victory" in the Pursuit of Human Longevity S. Jay Olshansky

Crowdfunding and Crowdsourcing of Aging

Science

Keith Comito

Inhibition of the Mechanistic Target of Rapamycin (mTOR) -Rapamycin and Beyond

Dudley W. Lamming

The Emergence of Geroscience as an

Interdisciplinary Approach to the Enhancement of

Health Span and Life Span

Felipe Sierra

The Economic Promise of Delayed Aging Dana Goldman

For additional articles in this collection, see http://perspectivesinmedicine.cshlp.org/cgi/collection/ 